\title{
NON-PHARMACOLOGICAL MANAGEMENT OF ALZHEIMER'S DISEASE A QUALITATIVE STUDY, IN MAURITIUS
}

\author{
Smita Goorah ${ }^{1}$, Geeta Devi Dorkhy ${ }^{2}$ \\ ${ }^{1}$ Associate Professor, Department of Medicine, University of Mauritius, Member of the \\ Clinical Research Regulatory Council, Mauritius
}

${ }^{2}$ Student, Master of Public Health, University of Mauritius

\begin{abstract}
Introduction: The major form of dementia is Alzheimer's disease (AD). In Mauritius it was estimated in 2015 that around 10,000 persons had Alzheimer's disease from Alzheimer disease International report ${ }^{1}$. This represent $16 \%$ of the total population and it is expected to rise. Therefore, apart from pharmacological therapies, non-pharmacological treatment (NPT) which can improve cognitive performance such as cognitive training, occupational therapy, reminiscence therapy, are being highly investigated.
\end{abstract}

Aim and objective: To determine the outcome(s) and to highlight the effective strategies in the management of Alzheimer's Disease in Mauritius using NPT. Information obtained from this research will add to the current knowledge and expansion.

Materials and methods: The only NGO in Mauritius is "Alzheimer's Association", from where the persons with $\mathrm{AD}$ were recruited. Non-interventional methods of qualitative study involving interviews of person with $\mathrm{AD}$, lasting 30-45 minutes were audio-recorded. An informed consent from the carer or patient-relative prior to starting was ensured. Both semistructured interviews and open-ended questions were used, relating to NPT. Thematic analysis in qualitative research, followed by coding and decoding raw data. Similar categories of data were grouped and themes emerged.

Results: In-depth responses of the person with AD related with their experiences, perceptions, opinions, feelings, and knowledge. Qualitative study $(n=20)$ emerged with 6 main themes. Among these, dependency on family identified as an important theme. It has also been associated as an important form of cognitive and functional engagement for person with AD.

Discussion: Non-pharmacological interventions has an important role to prolong the active age of older individuals, as well as to maintain quality of life.

Conclusion: There is still a greater demand on the market for non-pharmacological interventions and Mauritius should plan and devise national guidelines to deal with this unmet proportion of elderly so as to curb for future health equality and stability.

Keywords: Alzheimer's disease, Non-pharmacological Treatment, Cognitive training, Occupational therapy, Elderly people

\footnotetext{
${ }^{1}$ Alzheimer's Disease International. World Alzheimer Report 2018 The state of the art of dementia research: New frontiers. UK; 2018. 48 p.
} 


\section{INTRODUCTION}

No drug can cure Alzheimer's disease (AD) but non-pharmacological therapy (NPT) has shown to slow down the process till we have a cure ${ }^{2}$. (Nelson L, 2015). AD is still a chronic and serious condition especially since it is the third cause of death in year 2016, in high income countries according to World Health Organization ${ }^{3}$. (WHO, 2018) Therefore, any intervention which can delay the onset of symptoms in $\mathrm{AD} /$ dementia will have a big impact on patients and their families.

So far, no research has been done on the Alzheimer patient in Mauritius, little is known on the NPT, therefore to be able to better understand the current situation this project was conducted with the population of Alzheimer's patient at the NGO at Belle Rose in Mauritius.

Many side effects of drug therapy for AD is known in patients from the use of Memantine, Rivastigmine, which are acetylcholine esterase inhibitors. The non-pharmacological management was most interesting topic to find out the different outcomes and various aspects into the management of person with Alzheimer's disease.

\section{MATERIALS AND METHODS}

Qualitative research is a non-statistical inquiry. It is based on the analysis of a social phenomenon affecting the lives of the individual or as part of their lived- experience. Therefore, qualitative researches have an interest into developing new concepts and try to develop the power to understand theories or a hypothesis. Hence qualitative research is to understand the people from their own perspectives and their own frames of reference, how they live their daily lives, experiencing reality ${ }^{4}$ (Corbin \& Strauss, 2008). "Grounded theory is a hypothesis-generating analytic technique whereby raw interview or observation data are systematically analysed in order to explain a social or psychological process 5 " (Glaser \& Strauss, 1967)

Ethical clearance for the project was obtained both from the "ethical committee the Ministry of Health and Quality Of Life", Mauritius and the Consultant, "Ministry of Social Security, National Solidarity \& Reforms Institutions". Information about the study was provided to all participants at the Association Alzheimer and subsequently invited to participate.

Participation was on voluntary basis and they could leave at any point of time during the study. Information sheet was also provided and relevant details of the project was provided to the patients as well patient's carer prior to the start.

Consent was obtained through the care giver and the patient. The process and the aim of the study was explained in simple Creole/French language. Verbal consent from both parties

\footnotetext{
${ }^{2}$ Nelson L, Tabet $\mathrm{N}$ et al. Slowing the progression of Alzheimer's disease; what works, 2015;23(Pt B): 193-209

${ }^{3}$ World Health Organization, top 10 causes of death, 2018 report

${ }^{4}$ Glaser B G, Strauss A L 1967 The discovery of Grounded Theory, Aldine, New York

${ }^{5}$ Glaser B G, Strauss A L 1967 The discovery of Grounded Theory, Aldine, New York
} 
(carer and patient) and written consent was obtained from the carer/ care giver and /or the patient

\section{i. Selection and Description of Participants}

\section{Table 1: The inclusion and exclusion criteria}

\begin{tabular}{|l|l|}
\hline Inclusion criteria & $\begin{array}{l}\text { Population sample: All the participants were recruited from the } \\
\text { 'Alzheimer's Association' Centre at Belle Rose, Mauritius. The } \\
\text { elderly population aged } \geq 60 \text { years were included. }\end{array}$ \\
\hline $\begin{array}{l}\text { Language: All the participants were local people and creole and } \\
\text { French language was commonly used. } \\
\text { There was no dementia diagnosis. }\end{array}$ \\
\hline No other neuropsychiatric disorders other than AD \\
\hline Population sample: Patients other than those found at the 'Alzheimer \\
\hline Association' Centre. Person aged $\leq 59$ years \\
\hline Other neuropsychiatry diagnosis other than Alzheimer's Disease
\end{tabular}

All Participants were recruited from the Alzheimer's Association, at Belle Rose, Mauritius. Sample size was obtained till theoretical saturation reached and no new ideas, data emerged. Interview questions were open ended and clear consisting of 20 open-ended questions. Some instructions were provided for exploring more details, and to metamorphose between topics. The interviewer proceeded to the interview process by engaging the patient in an initial discussion of what are the main types of non-pharmacological therapy (NPT) and how much they were involved. Qualitative research proceeded as mostly-open ended questions with probing.

All interviews were audio recorded and then later transcribed. Person living with Alzheimer's disease own experiences was written down, noted and recorded with the use of smartphone and later translated from creole or French language to English using google translation. Spoken words and observable behaviour of the individuals formed part in developing a concept. Eventually these were grouped together as particular concepts/themes which generated the field notes.

\section{ii. Technical Information}

Phenomenological interpretative analysis method in qualitative research is an ongoing process of coding data and decoding and grouping similar chunk of data together. 
The following steps are required:

Collecting data (Creole language), proceed to coding of data, followed by "categorizing bits of data and then interpreting interview data and writing field notes" (Strauss \& Corbin, 1990). "Initial coding involved describing and labelling units of data". Also "similar kinds of information are grouped together into categories". Then "relating different ideas and themes to one another", (Rubin and Rubin, 1995). This process was repeated until all raw data are coded once.

This step also involves literature reading (next section; Table 1). Together with the "naïve understanding and the authors' pre-understanding, these were reflected by using suitable literature to form a comprehensive understanding" " (Lindseth \& Norberg, 2004). Lastly interpretation takes place.

\section{iii. Procedures}

No software was used for data processing and analysis in qualitative study. At time of study, there was no exposure to software material for the duration of the research.

A number of studies were searched for online database using Google Scholar and PubMed. Included studies were related to Alzheimer's disease and dementia of qualitative study methods. The following key terms were searched across all the online databases:

“Alzheimer's Disease", "Dementia", "lived-experience”, “dependency", “emotions", "quality of life", "physical exercise", "group singing", "music playing", "family and carer", "anxiety", "decision-making", "interactions with others", "having a pet", "outdoor activities", "awareness into illness". Table 2 below provides quotations from the individual studies relating them to the main themes and sub-themes in qualitative research.

Table 2: Main themes/sub-themes and related studies/quotations

\begin{tabular}{|c|c|}
\hline $\begin{array}{l}\text { Related Main Themes/ Sub- } \\
\text { themes }\end{array}$ & Related Studies/ Quotations \\
\hline $\begin{array}{l}\text { Explore physical activity in } \\
\text { AD patients. }\end{array}$ & $\begin{array}{l}\text { - Malthouse and Fox, (2014) in South West England } \\
\text { conducted qualitative study. He used semi-structured } \\
\text { interviews to explore physical activity in AD patients. } \\
\text { Results: The findings were a complex mix of theme: } \\
\text { 'self', 'others' and 'couple'. Physical activity showed a } \\
\text { link with the progression of dementia. }\end{array}$ \\
\hline
\end{tabular}

- "Mental exercise was frequently used means for

\footnotetext{
${ }^{6}$ Herbert J. Rubin \& Irene S. Rubin, Qualitative Interviewing (2nd ed.): The Art of Hearing Data, $\left(2^{\text {nd }}\right.$ edn,2005)

${ }^{7}$ Herbert J. Rubin \& Irene S. Rubin, Qualitative Interviewing (2nd ed.): The Art of Hearing Data, $\left(2^{\text {nd }}\right.$ edn,2005)

8 Lindseth A, Norberg A. et al. A phenomenological hermeneutical method for researching lived experience, $2004 ; 18(2): 145-53$.
} 


\begin{tabular}{ll}
\hline $\begin{array}{l}\text { decreasing the dementia risks in Australia". (Low and } \\
\text { Anstey, 2009) }\end{array}$ & \\
\hline $\begin{array}{l}\text { "Knowledge on AD and } \\
\text { ethnic belonging" }\end{array}$ & $\begin{array}{l}\text { Ayalon and Areán, (2004) indicated that "Anglo older } \\
\text { adults are significantly more knowledgeable about AD } \\
\text { than African American, Asian, and Latino older } \\
\text { adults." So, knowledge of AD was an important factor } \\
\text { between Latino to Anglo older adults. Conclusions: } \\
\text { Lack of information in certain ethnic groups was a } \\
\text { disadvantage, as these services were not included and } \\
\text { therefore barriers have to be addressed first. }\end{array}$
\end{tabular}

"Awareness into illness"

- Caddell \& Clare (2011) reported the "PWD have insight into changes in their cognitive capacity" in particular, changing awareness and memory function were identified first.

- Werezak and Stewart (2009) reported "changing levels of awareness" as they had proposed the theory of a "continuous process at each stage of the condition the process of adjustment between these stages"

"Being a person with dementia means living with forgetfulness" (personal sphere)
- (Mazaheri et al., 2014) Participants mainly described "dementia as forgetfulness" as they discussed their "condition associated consequences of living with dementia"

- Methods: Fifteen PWD were interviewed from Iran

- Results: The themes comprised of: "Being a person with dementia means living with forgetfulness (personal sphere), living with forgetfulness in the private sphere means feeling incompetent but still loved, living with forgetfulness in the public sphere means feeling confident and secure but also isolated". Conclusions "Living with dementia for the participants meant living with forgetfulness". They experienced "feeling incompetent but still loved within their families and feeling confident and secure but also isolated in the society"
"Experience of living with dementia"
- Górska, Forsyth and Maciver, (2018) A qualitative research 
persons with dementia

Ageing leads to both adaptation in some while other have maladaptation affecting behaviours in people's interactions and cognition.
- Results demonstrated quality and developed three themes:

i. Firstly, "the main condition-related changes experienced by people with dementia impact upon various areas of people's lives".

ii. "That amidst these changes, strived to maintain continuity in their lives by coping strategies".

iii. "The role of contextual factors".

- National Alliance for Caregiving, (2015) reported that time changes everyone especially the carer's burden and responsibilities since carer's show fatigue and tiredness.

- Ashida et al. (2018) studied the "need to provide care and the changes in family relationships". "Perceptions that family members are contributing as expected has implications on how stress is processed"

- It is a big deal of stress in patients when they are left on own, unsupported as Neufeld \& Harrison (2003) carried out a qualitative study where women showed no support, unmatched aids and expectations in caring for a relative with dementia.
- (Swall et al., 2017) conducted a qualitative interventional study. He used video-recorded observations to "illuminate meanings of care for people with $\mathrm{AD}$ in their encounters with a therapy dog"..

- Results: The main theme was "Using one's own resources and abilities as a human being", which meant "being the person one can be and distancing oneself from the symptoms of $\mathrm{AD}$ during the time with the dog" Conclusions: Feelings of "empathy and altruism, which allowed for a sense of joy and tenderness, which may induce a sense of self-worth". (Bodily movement, speech, and eye contact was also reported).

- Kessler et al. (2012) studied the ageing anxiety and health anxiety/worries within a context structure of health psychology, physiology and sociocultural background. 
"decision-making process used by individuals in dementia research and their opinions for future decision-making". Qualitative methods with 39 cognitively impaired subjects who joined a dementia and interviews audio recorded and later transcribed.

- Results: Perspectives differed on how decisions were made while there was only fair agreement on final decision made by surrogates.

Family Interactions and AD

- “Ameliorating caregiving burden through patient's education, support provision, and environmental modifications" (Schulz et al., 2003). increasing efforts to consider caregiving at family-level process

- "Families may benefit from engaging in shared decision-making processes, caregiving expectations and plans to minimize gaps" (Cené et al., 2016).

\section{RESULTS}

Results in qualitative study were displayed in the table form and flowcharts. During the process of phenomenological interpretive study, the 'meaning unit' has been 'condensed' and the main 'theme' derived as shown in Table 3, Table 4 below. However, the raw meaning has not been changed into some different meaning. This is known as 'researcher bracketing'. The "sub-themes", "themes", and "main theme" were reflected in literature to form a more proper understanding.

Table 3: Coding and decoding in qualitative study design

\begin{tabular}{|c|c|c|c|}
\hline Meaning unit & Condensation & Sub $\square$ theme & Theme \\
\hline $\begin{array}{l}\text { "Where is my } \\
\text { daughter-in- law. } \\
\text { When will she } \\
\text { come...she will } \\
\text { forget me ..how will } \\
\text { I go home" F,75 }\end{array}$ & $\begin{array}{l}\text { Anxious } \\
\text { Feeling alone } \\
\text { Asking for family }\end{array}$ & $\begin{array}{l}\text { Role of family } \\
\text { affects lives of } \mathrm{AD} \\
\text { patients }\end{array}$ & $\begin{array}{l}\text { Importance of } \\
\text { family }\end{array}$ \\
\hline
\end{tabular}

\section{Table 4: Development of subtheme, themes and main themes in qualitative study}




\begin{tabular}{|l|l|l|}
\hline Subthemes & Themes & Main themes \\
\hline $\begin{array}{l}\text { "For me every time I am } \\
\text { sick I do not want to do } \\
\text { anything, my grandson, my } \\
\text { son takes me to the private } \\
\text { doctor, buys my medicines } \\
\text { and gives me ..."F,65 }\end{array}$ & $\begin{array}{l}\text { Taking care of mother } \\
\text { Caring for elders }\end{array}$ & Family as an important unit \\
\hline $\begin{array}{l}\text { "I get a lot of friends here, I } \\
\text { like playing dominoes, to } \\
\text { talk here, and visiting } \\
\text { places, I like it here..."M,81 }\end{array}$ & $\begin{array}{l}\text { Need for company } \\
\text { Need for social interactions }\end{array}$ & $\begin{array}{l}\text { Socializing among people } \\
\text { Interacting with others is } \\
\text { important }\end{array}$ \\
\hline
\end{tabular}

\section{THEMES}

Results of this research emerged as all the themes with similar significance were grouped together and form the following 7 main themes as identified:

- "Active", " happy", "friends"

- "I like to sing", "I can play instrument"

- "I care for the dog"

- "Forget", "I don't remember"

- "I am old now", "I can help"

- "I love my grandchildren" "They take me to the doctor"

- "I can recall", "old memories"

The flowchart below (Figure 1, Figure 2) depicts the initial set of raw data in condensed form, further analysed and grouped together to demonstrate the role of family as identified by the persons with AD. Here, the emotions were also displayed in association with the important part of qualitative studies.

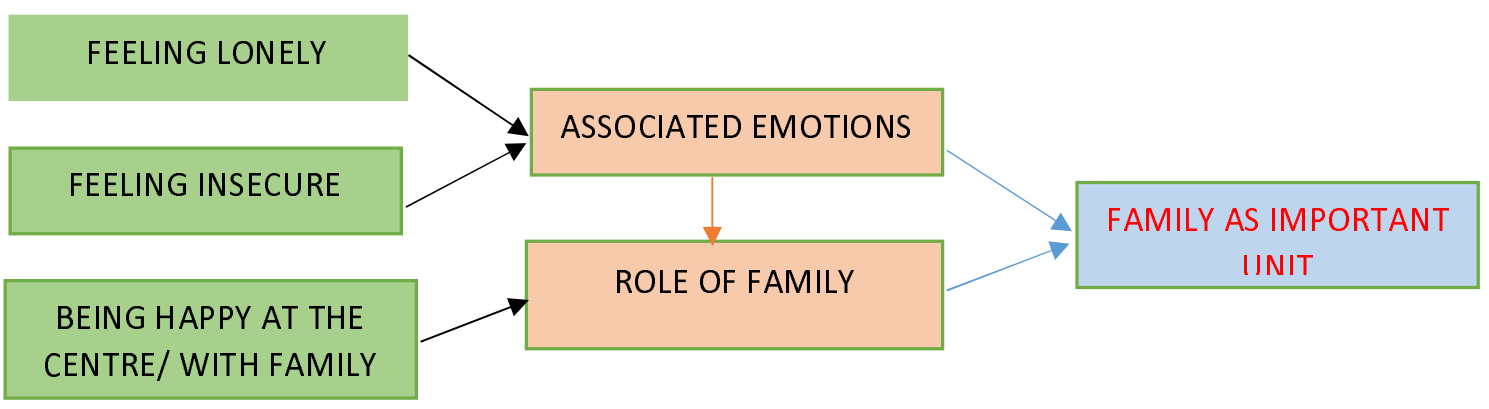

Figure 1: Flowchart showing the coding, the subthemes, and the main themes. The emotions associated with person with AD expressed and grouped together, highlighting the importance of family as NPT. 


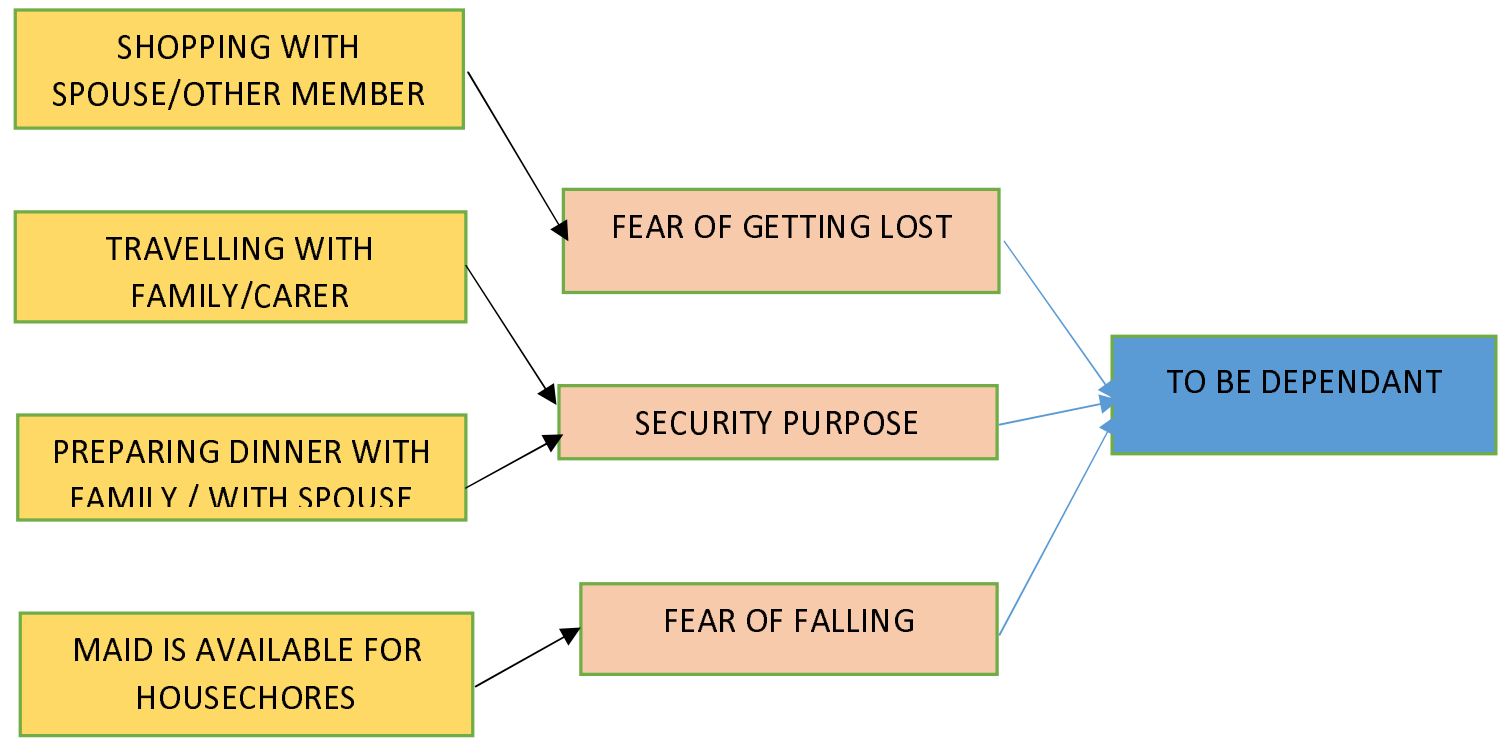

Figure 2: Flowchart showing the coding, the subthemes, and the main themes. The activities of daily living were mostly associated with security of the individual and management of everyday living purposes, which displayed a certain level of being a dependant living person with $A D$, as qualitative study joins the functional capacity and emotions.

\section{Theme 1: Participation in activities}

Patients talked about their level of activity. Physical activity mentioned by patients were yoga, stretch exercise, breathing exercise. Physical exercise was noted as being important for the patients. It is also a practice of healthy behaviours. Patients have reported that they regularly exercise at the Centre as well as at home.

"I have learnt to do stretch exercise" M, 70. "I do breathing exercise and yoga classes" F, 86.

"I do mild to moderate physical activity like having a walk in the locality area/playground for few minutes...I am active" F, 83.

Others prefer to practice yoga and breathing exercise at home: "one particular days, when I stay at home, in the morning time I do practice yoga and breathing exercises, because we have learnt this from here..."M, 76

\section{Theme 2: Singing and Music}

Music was much appreciated at the Centre especially since it offer music and singing sessions to the elderly. They were active participants also.

"I like singing and I play piano at Church" M, 72. "I like to sing and dance here...the centre has such programmes" F, 64. "I like music, I was a teacher" F, 63. "I can sing with children" $\mathrm{F}, 68$. 


\section{Theme 3: Affection and caring}

Caring for pets. Many patients reported that they spent time with their pet at home,

"The dog is like security guard at home... I feed him only once a day, bath the dog" F, 85

"I like birds, they can sing for me" F, 89

\section{Theme 4: Knowledge on AD}

Patient was able to describe their symptoms as loss in personal belonging and forgetfulness symptoms, related to correct educational background on the disease process and manifestation, arising fear in persons with $\mathrm{AD}$.

“..the disease affects my life as I have loss my key, my wallet” M, 70

“..I reached the shop and I was standing out there..,I forgot what to buy..., 'to forget' is part of the illness"M,69

\section{Theme 5: Level of dependency and level of autonomy}

Issues relating to ageing and demotivation, low energy levels. Although no physical disability was present, patient was depressed.

"I am old now, I fell tired, I can't do much" M, 62.

Assistance was required at home for cleaning and cooking as some patients mentioned being more dependent. Some patients have reported that a maid was available to do the cleaning at home and cooking part while others shared the chores.

"I do all the house chores and I am so much tired that my son scolds me all the time..my house should be clean that's all I like" F, 69

Furthermore, there was no mention of "being lost" while traveling alone however, they were under care and supervision.

"I usually go to short distances, or take one bus directly to and from home, go to seaside for some time..." M, 65

".. I can drive for short distance, to known places, accompanied by my wife, ... otherwise I take the bus for long distances and accompanied by a relative...", M,60

"I am travelling in my daughter's car accompanied by a driver who drops me to the center, and to supermarket to do shopping and then back home..." F, 79

The persons with $\mathrm{AD}$ were never left on their own, while some travelled over short distances either by the bus alone, or a driver would drop them at the center and pick up

\section{Theme 6: Family support}

"I like spending time with family,..I like spending time with grandchildren, F,82 . Describing family as an important unit for support. 
One patient reports when I fall sick my children and grandchild takes me to the doctor, they buy my medicine and give me ...I love them”F, 86

"I can speak French with my grandchildren, as their mother also does same ..I am learning too" learning at all phases of life, F,60

One persons with AD showed worriedness and lack of security and repeatedly said: "She will forget me here, how will I go home..I am afraid, to walk down the lane too many bad guys, what will happen if they hit and snatch my bag..can you call my daughter-in-law please", F,60

\section{Theme 7: Recall memory of the past}

$\mathrm{AD}$ patients recall their past memories. The long term memory were detailed in long conversations, at times, relating to their childhood and work.

"I listen to mother..she tells me do this ..." F, 87

"I used to do all heavy work, cut cane, take care of my 4 children, cook 'farata', I have worked enough...I can travel now and rest, I have married all my sons ..I am free person" F, 64

AD patients showing derailment with poor recall memory, and say little, not participating or failed to understand the conversation, referring to "the thing" all the times showing aphasia "This centre is for the mentally disturbed patients? I think that's why I am here, I am mentally sick?" M, 68 .

\section{DISCUSSION}

The sampled population was already exposed to both pharmacological and NPT for AD. NPT included the occupational therapy, speech therapy, and behavioural cognitive therapy, reminiscence therapy, group work activities, psychotherapy. These activities engaged the person with $\mathrm{AD}$ at the Centre in various ways so the findings in qualitative research was spoken, interactive discussions and interviews that captured the patients with AD livedexperiences. In addition, the main themes "active", "happy", "like", "care" contributed towards the health of the people with $\mathrm{AD}$. As new data emerges it adds to future knowledge. It is important for Mauritius to carry out further research work to focus on NPT and to plan national guidelines and integrated, mixed treatment for AD. Alzheimer's disease remains an important topic and the patient should be taken care of with multidisciplinary actors and stakeholders acting together to provide evidence-based knowledge and practice.

\section{Weakness in qualitative research}

Interview is a time consuming process. The disease process manifest itself as many symptoms identified as barriers in qualitative research namely:

a. Patients are impatient and don't like to sit for too long time with strangers

b. They show poor responsiveness towards the researcher

c. They may be aggressive at times

d. Their language problems, agnosia is present

e. Difficulty in understanding instructions (communication problems)

f. Hearing problems, poor vision and age-related problems which limit the accuracy of data 


\section{REFERENCES}

1. Alzheimer's Disease International. World Alzheimer Report 2018 The state of the art of dementia research: New frontiers. UK; 2018. 48 p.

2. Nelson L, Tabet $\mathrm{N}$ et al. Slowing the progression of Alzheimer's disease; what works, 2015;23(Pt B):193-209

3. World Health Organization, top 10 causes of death, 2018 report: Available from: https://www.who.int/news-room/fact-sheets/detail/the-top-10-causes-of-death

4. Glaser B G, Strauss A L 1967 The discovery of Grounded Theory, Aldine, New York

5. Herbert J. Rubin \& Irene S. Rubin, Qualitative Interviewing (2nd ed.): The Art of Hearing Data, $\left(2^{\text {nd }}\right.$ edn,2005)

6. Lindseth A, Norberg A. et al. A phenomenological hermeneutical method for researching lived experience, 2004;18(2):145-53. 


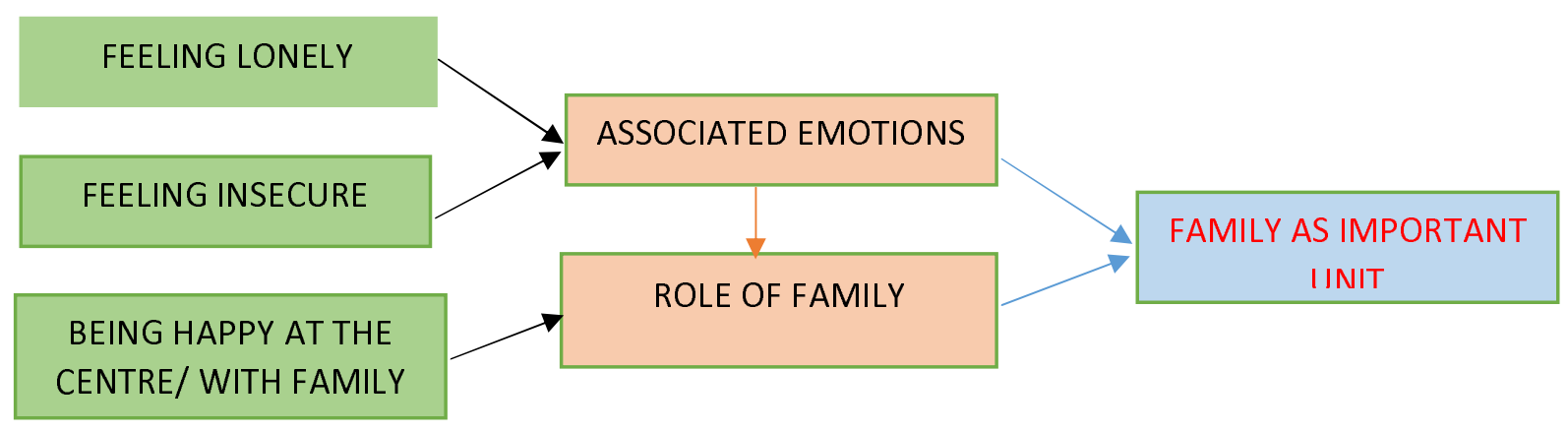

Figure 1: Flowchart showing the coding, the subthemes, and the main themes. The emotions associated with person with AD expressed and grouped together, highlighting the importance of family as NPT.

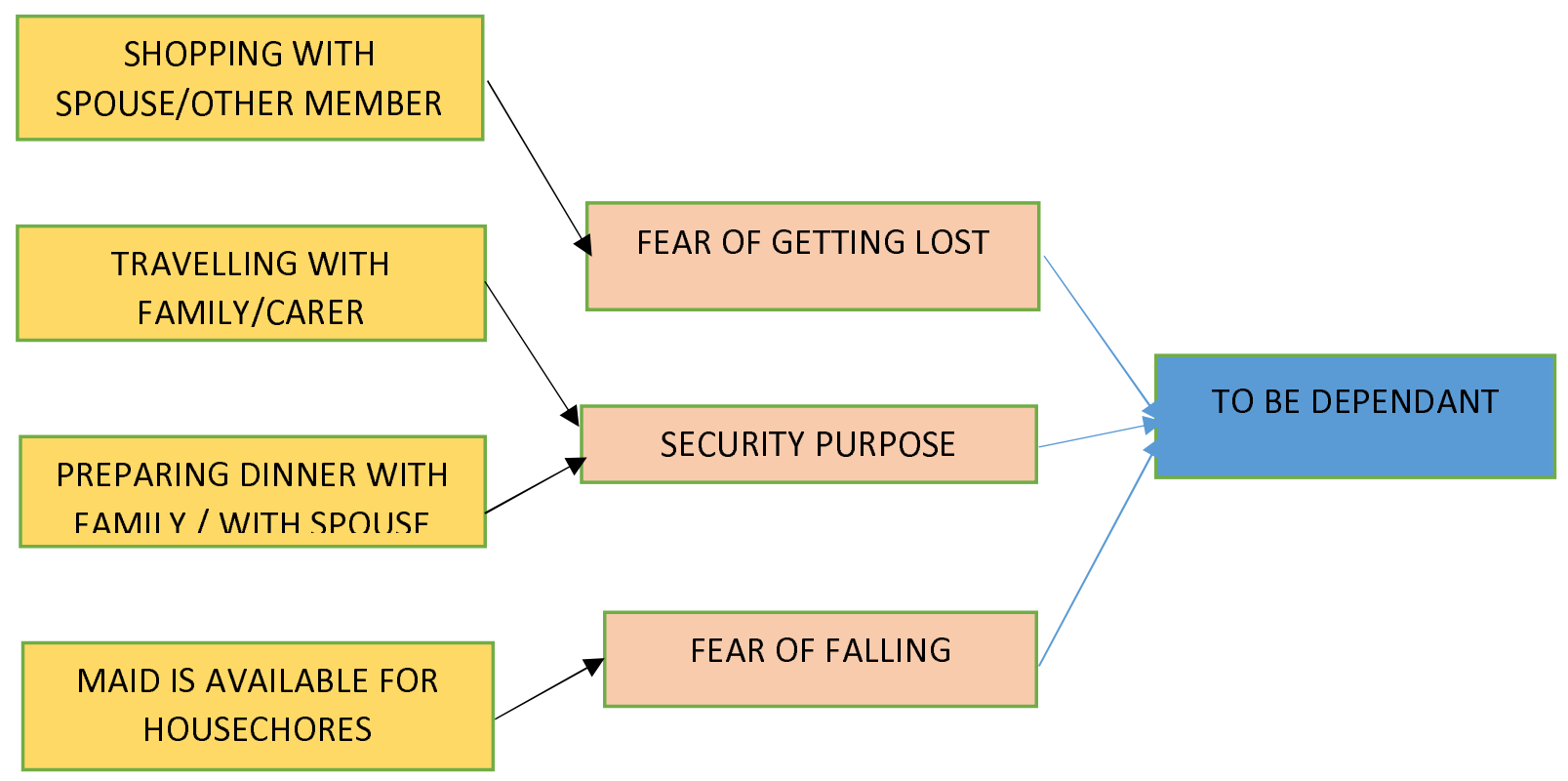

Figure 2: Flowchart showing the coding, the subthemes, and the main themes. The activities of daily living were mostly associated with security of the individual and management of everyday living purposes, which displayed a certain level of being a dependant living person with $A D$, as qualitative study joins the functional capacity and emotions. 


\section{Table 1: The inclusion and exclusion criteria}

\begin{tabular}{|l|l|}
\hline Inclusion criteria & $\begin{array}{l}\text { Population sample: All the participants were recruited from the } \\
\text { 'Alzheimer's Association' Centre at Belle Rose, Mauritius. The } \\
\text { elderly population aged } \geq 60 \text { years were included. }\end{array}$ \\
\hline $\begin{array}{l}\text { Language: All the participants were local people and creole and } \\
\text { French language was commonly used. } \\
\text { There was no dementia diagnosis. }\end{array}$ \\
\hline No other neuropsychiatric disorders other than AD \\
\hline Exclusion criteria & $\begin{array}{l}\text { Population sample: Patients other than those found at the 'Alzheimer } \\
\text { Association' Centre. Person aged } \leq 59 \text { years }\end{array}$ \\
\hline Other neuropsychiatry diagnosis other than Alzheimer's Disease
\end{tabular}

Table 2: Main themes/ sub-themes and related studies/ quotations

Related Main Themes/Sub- Related Studies/ Quotations
themes

Explore physical activity in $\quad$ - Malthouse and Fox, (2014) in South West England AD patients. conducted qualitative study. He used semi-structured interviews to explore physical activity in $\mathrm{AD}$ patients. Results: The findings were a complex mix of theme: 'self', 'others' and 'couple'. Physical activity showed a link with the progression of dementia.

- "Mental exercise was frequently used means for decreasing the dementia risks in Australia". (Low and Anstey, 2009)

\begin{abstract}
"Knowledge on AD and ethnic belonging"
\end{abstract}

- Ayalon and Areán, (2004) indicated that "Anglo older adults are significantly more knowledgeable about $\mathrm{AD}$ than African American, Asian, and Latino older adults." So, knowledge of $\mathrm{AD}$ was an important factor between Latino to Anglo older adults. Conclusions: Lack of information in certain ethnic groups was a disadvantage, as these services were not included and therefore barriers have to be addressed first.

\section{"Awareness into illness"}




\section{"Being a person with dementia means living with forgetfulness" (personal sphere)}

insight into changes in their cognitive capacity" in particular, changing awareness and memory function were identified first.

- Werezak and Stewart (2009) reported "changing levels of awareness" as they had proposed the theory of a "continuous process at each stage of the condition the process of adjustment between these stages"

\section{"Experience of living with dementia"}

- (Mazaheri et al., 2014) Participants mainly described "dementia as forgetfulness" as they discussed their "condition associated consequences of living with dementia"

- Methods: Fifteen PWD were interviewed from Iran

- Results: The themes comprised of: "Being a person with dementia means living with forgetfulness (personal sphere), living with forgetfulness in the private sphere means feeling incompetent but still loved, living with forgetfulness in the public sphere means feeling confident and secure but also isolated". Conclusions "Living with dementia for the participants meant living with forgetfulness". They experienced "feeling incompetent but still loved within their families and feeling confident and secure but also isolated in the society"
- Górska, Forsyth and Maciver, (2018) A qualitative research

- Results demonstrated quality and developed three themes:

i. Firstly, "the main condition-related changes experienced by people with dementia impact upon various areas of people's lives".

ii. "That amidst these changes, strived to maintain continuity in their lives by coping strategies".

iii. "The role of contextual factors". 
persons with dementia
- National Alliance for Caregiving, (2015) reported that time changes everyone especially the carer's burden and responsibilities since carer's show fatigue and tiredness.

- Ashida et al. (2018) studied the "need to provide care and the changes in family relationships". "Perceptions that family members are contributing as expected has implications on how stress is processed"

- It is a big deal of stress in patients when they are left on own, unsupported as Neufeld \& Harrison (2003) carried out a qualitative study where women showed no support, unmatched aids and expectations in caring for a relative with dementia.

\section{Ageing leads to both adaptation in some while other have maladaptation affecting behaviours in people's interactions and cognition.}

- (Swall et al., 2017) conducted a qualitative interventional study. He used video-recorded observations to "illuminate meanings of care for people with $\mathrm{AD}$ in their encounters with a therapy dog"..

- Results: The main theme was "Using one's own resources and abilities as a human being", which meant "being the person one can be and distancing oneself from the symptoms of $\mathrm{AD}$ during the time with the dog" Conclusions: Feelings of "empathy and altruism, which allowed for a sense of joy and tenderness, which may induce a sense of self-worth". (Bodily movement, speech, and eye contact was also reported).

- Kessler et al. (2012) studied the ageing anxiety and health anxiety/worries within a context structure of health psychology, physiology and sociocultural background.
- Black, Wechsler and Fogarty, (2013) examined the "decision-making process used by individuals in dementia research and their opinions for future decision-making”. Qualitative methods with 39 cognitively impaired subjects who joined a dementia and interviews audio recorded and later transcribed.

- Results: Perspectives differed on how decisions were made while there was only fair agreement on final decision made by surrogates. 


\section{Family Interactions and AD}

- "Ameliorating caregiving burden through patient's education, support provision, and environmental modifications" (Schulz et al., 2003). increasing efforts to consider caregiving at family-level process

- "Families may benefit from engaging in shared decision-making processes, caregiving expectations and plans to minimize gaps" (Cené et al., 2016).

Table 3: Coding and decoding in qualitative study design

\begin{tabular}{|c|c|c|c|}
\hline Meaning unit & Condensation & Sub $\square$ theme & Theme \\
\hline $\begin{array}{l}\text { "Where is my } \\
\text { daughter-in- law. } \\
\text { When will she } \\
\text { come... she will } \\
\text { forget me ..how will } \\
\text { I go home" F,75 }\end{array}$ & $\begin{array}{l}\text { Anxious } \\
\text { Feeling alone } \\
\text { Asking for family }\end{array}$ & $\begin{array}{l}\text { Role of family } \\
\text { affects lives of } \mathrm{AD} \\
\text { patients }\end{array}$ & $\begin{array}{l}\text { Importance of } \\
\text { family }\end{array}$ \\
\hline
\end{tabular}

Table 4: Development of subtheme, themes and main themes in qualitative study

\begin{tabular}{|l|l|l|}
\hline Subthemes & Themes & Main themes \\
\hline $\begin{array}{l}\text { "For me every time I am } \\
\text { sick I do not want to do } \\
\text { anything, my grandson, my } \\
\text { son takes me to the private } \\
\text { doctor, buys my medicines } \\
\text { and gives me ..."F,65 }\end{array}$ & $\begin{array}{l}\text { Taking care of mother } \\
\text { Caring for elders }\end{array}$ & Family as an important unit \\
\hline $\begin{array}{l}\text { "I get a lot of friends here, I } \\
\text { like playing dominoes, to } \\
\text { talk here, and visiting } \\
\text { places, I like it here..."M,81 }\end{array}$ & $\begin{array}{l}\text { Need for company } \\
\text { Need for social interactions } \\
\text { Like to be here }\end{array}$ & $\begin{array}{l}\text { Socializing among people } \\
\text { Interacting with others is } \\
\text { important }\end{array}$ \\
\hline
\end{tabular}

